\title{
Unemployment and Well-Being of Europeans Across the Life Cycle: The Role of Countries' Macroeconomic Situation
}

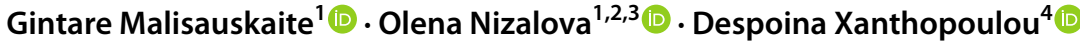

Accepted: 28 September 2021 / Published online: 7 February 2022

(c) The Author(s) 2022

\begin{abstract}
Unemployment impairs individuals' well-being and health and there is some empirical evidence showing that macroeconomic conditions can moderate these effects. This paper goes a step further and investigates differences in how macroeconomic indicators of European countries' economic situation relate to individual subjective health and well-being, and also moderate the relationship between individual labour market exclusion and these outcomes across age groups: young individuals (aged 15-29), prime working age adults (aged 30-49, base category) and pre-retirement age adults (aged 50-64). We used two different macroeconomic indicators to define macroeconomic situation: country-level unemployment rate and gross domestic product (GDP). Both indicators were disaggregated into long-term economic trend and business cycle shocks using Hodrick-Prescott filtering to allow distinguishing between expected and unexpected change in macroeconomic circumstances. We used the European Social Survey individual-level data from 35 European countries for 2002-2014. Multi-level analysis with three levels were run for men and women separately. Results revealed differences in how individual-level unemployment related to well-being depending on the age group, with pre-retirement age group adults' health and well-being suffering the most. Also, macroeconomic indicators were found to moderate the relationship between individual-level unemployment and subjective health and well-being with some noticeable differences between age groups, and with GDP trend having the most sizeable influence.
\end{abstract}

Keywords European age cohort analysis · Macroeconomic conditions $\cdot$ Subjective health and well-being · Unemployment

Gintare Malisauskaite

G.Malisauskaite@kent.ac.uk

1 Personal Social Services Research Unit (PSSRU), University of Kent, Canterbury, UK

2 Centre for Health Services Studies, University of Kent, Canterbury, UK

3 School of Economics, University of Kent, Canterbury, UK

4 School of Psychology, Aristotle University of Thessaloniki, Thessaloníki, Greece 


\section{Introduction}

Empirical evidence shows that unemployment impairs individuals' well-being and health (Cheng \& Chan 2008; De Witte, 2005; Guardiola \& Guillen-Royo, 2015; McKee-Ryan et al., 2005; Sverke et al., 2002; Voßemer \& Eunicke, 2015) and that the strength of these individual-level effects may vary across poorer and richer countries (Eichhorn, 2013; Nizalova et al., 2021; Wulfgramm, 2014). However, previous studies have not explored potential differences across working age groups: youth, those in pre-retirement, and those in between the two.

Looking at age differences is relevant because empirical evidence suggests that (the possibility of) losing one's job frustrates employees' basic psychological needs for autonomy, competence and relatedness across all age groups, but most strongly among older workers (Stynen et al., 2015). This implies that unfavourable labour market conditions are more likely to be perceived by older employees as hindrances, affecting their health and wellbeing more strongly than that of their younger counterparts. In addition, age was found to relate to how unemployment influences individuals' health and well-being. There is evidence showing that unemployment has a more unfavourable impact on middle-aged men in comparison to younger or older men (Broomhall \& Winefield, 1990; Rowley \& Feather, 1987). It is possible that younger and older men have more freedom and fewer responsibilities, while family demands and obligations make the unemployment experience for middleaged men more difficult to handle.

In this study we use individual-level data for the period from 2002 to 2014 from the European Social Survey (ESS) to investigate age differences regarding the relationship between individual-level unemployment and (impaired) self-reported health and wellbeing (i.e., unhappiness and life dissatisfaction). Also, we test the moderating role of specific macro-level indicators of countries' economic situation (i.e., unemployment rate and gross domestic product expressed as trends and business cycle fluctuations). Finally, we test effects by gender since unemployment experiences have been found to differ between men and women (Artazcoz et al., 2004; Clark et al., 2010; Connell, 1991, 1995; Paul \& Moser, 2009).

This paper contributes to the existing literature in the following ways. First, we contribute to the unemployment literature by investigating potential differences across age groups regarding its link with health and well-being, as well as the role of macroeconomic indicators on this relationship. This is important because it will allow determining whether the conditions under which unemployment is more or less unfavourable for health and well-being is global for all employees, or whether it varies for different age groups. This knowledge would be relevant for both theory and practice. From a theoretical point of view, it will advance our understanding of how younger, middle-aged and older employees respond to unemployment and observing any differences in unemployment effects between these groups, which could be measured imprecisely or altogether disappear if groups were pooled together. From a practical point of view, our analysis could guide age-focused interventions aiming at mitigating the unfavourable outcomes of unemployment. Using a large data sample from most of Europe for this investigation adds value because it helps making more generalizable inferences.

Second, we contribute to the economics literature by allowing for a decomposition of the macroeconomic environment (Gross Domestic Product, GDP, and unemployment rate, UR) into trends and residuals by using the Hodrick-Prescott decomposition (Baum, 2004; Hodrick \& Prescott, 1997). Frequently, GDP and UR are used interchangeably with 
only one of them being chosen to represent the macroeconomic environment. However, arguably, these two indicators represent different aspects of a country's macroeconomic situation. By focusing on both and decomposing them into trends and shock terms we can inspect if they complement each other in explaining subjective health and well-being and their relationship with unemployment, and if it is the expected (trend) or unpredicted (residual) component that affects this relationship the most. These adjustments are important to allow for more accurate economic modelling and in making simple predictions of how macroeconomic changes may influence health and well-being based on employment status and age.

\subsection{Theoretical Framework}

There is evidence showing that the unfavourable impact of unemployment on individual health and well-being is moderated by the country's economic situation (Clark et al., 2010; Eichhorn, 2013; Heggeb $\varnothing$ \& Elstad, 2018; Nizalova et al., 2021; Oesch \& Lipps, 2013; Powdthavee, 2007; Wulfgramm, 2014). This is attributed to the different levels or resources and support available to unemployed individuals across countries. Also, it is argued that these moderating effects may depend on how a macroeconomic indicator is expressed. For instance, there is evidence suggesting that the macroeconomic environment cannot be fully represented by either GDP or UR, and that these two indicators should be accounted for jointly (Nizalova et al., 2021). However, it is not yet established how these effects differ across working age life cycle.

There are several theoretical approaches that may help explain how macroeconomic characteristics like countries' GDP or UR levels could affect health and well-being and moderate the impact of labour market (LM) status on health and well-being. According to conservation of resources (COR) theory (Hobfoll, 1989; Hobfoll et al., 2018), individuals strive to preserve and protect valued resources and to acquire additional resources in order to adapt successfully to their environment. These resources are important not only for their instrumental value, but also for their value in helping individuals cope with stress, prevent health impairments, and feel better. Hobfoll (1989) recognizes four types of resources: objects (e.g., a house or a car), conditions (e.g., employment), personal characteristics (e.g., self-efficacy) or energies (e.g., money). Considering that resources can be found at different levels of analysis (e.g., the individual-level or the societal-level), the flourishing economic situation of a country can be operationalized as an energy resource at the macro level of analysis that may promote employee health and well-being.

A central assumption of COR theory (Hobfoll, 1989, 2018) is that the availability of resources can buffer the negative consequences of threatening or demanding conditions that individuals face on their health and well-being. In this context, it may be argued that in countries that flourish economically (i.e., are characterized by higher levels of GDP), unemployed individuals will have access to an adequate pool of resources (e.g., unemployment benefits or better welfare system). Similarly, being unemployed in a country with a low unemployment rate may make it more likely to get easier access to unemployment benefits because of fewer people requiring them. Resource availability at the country-level of analysis could help individuals deal more effectively with the threatening condition (i.e., individual-level unemployment) they are facing, which could prevent decrements in their health and well-being. Indeed, Täht et al. (2020) found that the negative link between unfavourable LM conditions and well-being was weaker in more (financially) equal societies. To conclude, based on COR theory, it may be argued that the negative relationship 
between unemployment and subjective health and well-being will be weaker in countries with higher GDP and lower UR.

Contrary to COR theory (Hobfoll, 1989), based on relative deprivation theory (Crosby, 1984) one could argue that the unfavourable impact of unemployment on health and wellbeing will be stronger in conditions of higher GDP and lower UR because under such conditions unemployed individuals may feel particularly deprived. This theory explains that a discrepancy between the outcomes people obtain and the outcomes to which they feel entitled to elicit feelings of relative deprivation. Such an experience has been shown to result in decreases in health and well-being (Fryer, 1998). For example, someone with a high human capital (e.g., education, experience, skills) could feel entitled to have a job (with the expected income resulting from it), and if this person is unemployed, they are likely to feel deprived and experience impairments in health and well-being. If such person is unemployed when their country's economy is healthy or growing, or unemployment rate is low or falling, this may result in feeling even more deprived.

The proposition that the unfavourable impact of unemployment on health and well-being will be stronger (weaker) in countries that are better (worse) off economically can also be supported by social identity theory (Tajfel \& Turner, 1986). In line with this theory, individuals choose to be part of groups that permeate a positive identity to them, when compared to an out-group. In countries where unemployment is high, the unemployed people are more likely to compare themselves with other unemployed, who are closer to the norm group. In this way, they protect their self-evaluation and self-regard and experience smaller decrements in their health and well-being. Vice versa, in countries where unemployment is low, upward social comparisons or comparisons with others that are in wealthier positions are more likely resulting in lower self-regard (Tesser et al., 1988). For example, Eichhorn (2013) found that income inequality moderated the relationship between unemployment and life satisfaction in a way that the negative effect of unemployment on life satisfaction was weaker in societies with greater income inequality. Similarly, in countries with high levels of GDP, the individual-level unemployment experience could become worse as the 'norm' group, with which unemployed individuals compare, is more likely to be wealthier. In contrast, if GDP is falling, these unemployed individuals may compare themselves to the growing body of other individuals in a similar position.

This line of reasoning is also supported by attribution theory (Fiske \& Taylor, 1991), which explains how information gathered from the environment changes how specific individual events are perceived. Accordingly, people who are unemployed in countries where unemployment rates are high or GDP is low, are more likely to assign the cause of their condition to the environment that is outside of their control (i.e., external attribution) and less likely to assign the cause to internal aspects like their personal characteristics or motivation. Thus, when the cause of one's unemployment is attributed externally, its unfavourable effects on health and well-being are likely to be less severe. In contrast, being unemployed in a country with low unemployment rates and booming GDP, is more likely to be attributed internally, and the effects on health and well-being could be more unfavourable. Thus, predictions of this theory would contrast those of COR theory (Hobfoll, 1989), where better resources at the country level should lessen the negative impact of unemployment towards health and well-being.

This multitude of possible yet contrasting theoretical explanations makes formulating specific hypotheses regarding the way in which macroeconomic indicators may moderate the relationship between labour market status and individual health and well-being challenging. The effect of the macroeconomic situation could come through two channels: (a) it could act as an indicator of employment opportunities or (b) it could represent availability 
of country-level resources. Different age groups could be affected differently by these channels. Young people experience difficulties transitioning into adulthood and from education to work (Grosemans et al., 2018), however, they are more likely to rely on family support (Jacob, 2008; Kilpatrick \& Trew, 1985; McKee-Ryan et al., 2005). Older people in pre-retirement age could struggle more searching for a new job (Aysina et al., 2017), and feel relatively more deprived being unemployed (Stynen et al., 2015), but they tend to have accumulated more wealth and savings (Weller \& Wenger, 2019). Finally, the middleaged group is likely to be burdened by family responsibilities the most, as it is expected to capture most of the sandwich generation, who need to take care of their parents and their children simultaneously (Boyczuk \& Fletcher, 2016). This could make their unemployment experience particularly difficult. Consequently, it would be useful to explore how individual-level unemployment experience varies between different age groups and macroeconomic conditions. Thus, we focus on the following research questions that help structure our analysis:

Research Question 1: Does the relationship between individual-level unemployment and outcome measures (subjective health and well-being) vary across the three age groups?

Research Question 2: Does the relationship between the macroeconomic indicators and outcome measures (subjective health and well-being) vary across the three age groups?

Research Question 3: Does the macroeconomic environment moderate the relationship between individual-level unemployment and outcome measures (health and well-being), and do these moderating effects differ across the three age groups?

\section{Methods}

\subsection{Data and Analytical Strategy}

We used European Social Survey (ESS) data. The ESS is carried out every two years examining a range of issues, such as employment, income, education, housing, family, health, work-life balance, life satisfaction and other attitudes and behaviours. For the purposes of this study data is available for the period of 2002-2014 and 35 European countries. ${ }^{1}$

To answer the research questions, we used the model identified below (1). We ran mixed-effects multilevel regressions with three levels: individuals (i.e., level 1) nested in years (i.e., level 2), nested in countries (i.e., level 3). Regressions were run for males and females separately to account for gender differences, since men and women can experience unemployment differently, with women suffering less negative consequences (Paul \& Moser, 2009). Work could be seen as essential for male identity, due to the traditional role of men being the "breadwinners" in the family (Connell, 1991, 1995). This may explain why marriage and domestic roles, in general, function as protective factors only for unemployed women while, in contrast, increase the risk of mental health problems among unemployed men (Artazcoz et al., 2004).

Model:

\footnotetext{
${ }^{1}$ ESS offers data for 36 countries, but Kosovo has been excluded from analysis due to only 1 year of data being available within the ESS dataset and macro-level unemployment rate being missing in ILO estimates from World Bank. List of included countries available in Table 1.
} 
Table 1 Descriptive statistics of the samples used (by gender)

\begin{tabular}{|c|c|c|c|c|}
\hline & \multicolumn{2}{|l|}{ Male } & \multicolumn{2}{|l|}{ Female } \\
\hline & Mean & SD & Mean & SD \\
\hline \multicolumn{5}{|l|}{ Dependent variables } \\
\hline Subjective bad health & $2.045 * *$ & 0.848 & $2.138 * *$ & 0.877 \\
\hline Unhappiness & 3.713 & 1.907 & 3.707 & 1.984 \\
\hline Life dissatisfaction & $4.026 * *$ & 2.224 & $4.081 * *$ & 2.297 \\
\hline \multicolumn{5}{|l|}{ Explanatory variables } \\
\hline \multicolumn{5}{|l|}{ Macro variables } \\
\hline GDP level (trend-hp) & $10.423 * *$ & 0.403 & $10.377 * *$ & 0.423 \\
\hline GDP level (res-hp) & $0.010^{*}$ & 0.046 & $0.011^{*}$ & 0.048 \\
\hline Macr. unempl. (trend-hp) & $7.967 * *$ & 3.245 & $8.080 * *$ & 3.190 \\
\hline Macr. unempl. (res-hp) & -0.087 & 1.998 & -0.096 & 2.048 \\
\hline \multicolumn{5}{|l|}{ LM status of interest } \\
\hline Unemployed & $0.053 * *$ & & $0.043 * *$ & \\
\hline Young (15-29) & $0.226 * *$ & & $0.214 * *$ & \\
\hline Old (50-64) & 0.325 & & 0.328 & \\
\hline \multicolumn{5}{|l|}{ Other variables } \\
\hline Insecure employment & $0.138 * *$ & & $0.157 * *$ & \\
\hline Discouraged from work & 0.020 & & 0.019 & \\
\hline In education & 0.081 & & 0.080 & \\
\hline Retired & $0.074 * *$ & & $0.079 * *$ & \\
\hline Housework & $0.013 * *$ & & $0.161 * *$ & \\
\hline Other LM status & $0.041 * *$ & & $0.038 * *$ & \\
\hline Income & $5.977 * *$ & 2.777 & $5.593 * *$ & 2.785 \\
\hline Age & $41.504 * *$ & 13.387 & $41.743 * *$ & 13.209 \\
\hline Age-squared & $1901.783 * *$ & 1104.54 & $1916.951 * *$ & 1096.112 \\
\hline Secondaryeducation & $0.594 * *$ & & $0.554 * *$ & \\
\hline Tertiary education & $0.343 * *$ & & $0.375 * *$ & \\
\hline Married & 0.591 & & 0.589 & \\
\hline Divorced & $0.101 * *$ & & $0.171 * *$ & \\
\hline Year 2002 & $0.139 * *$ & & $0.132 * *$ & \\
\hline Year 2004 & 0.136 & & 0.135 & \\
\hline Year 2006 & 0.127 & & 0.124 & \\
\hline Year 2008 & $0.169 *$ & & $0.173^{*}$ & \\
\hline Year 2010 & $0.160 * *$ & & $0.167 * *$ & \\
\hline Year 2012 & $0.172 * *$ & & $0.177 * *$ & \\
\hline Year 2014 & $0.097 * *$ & & $0.092 * *$ & \\
\hline No. of obs & 81,451 & & 89,721 & \\
\hline
\end{tabular}

$* * p<0.01 ; * p<0.05$

Countries in analysis: Albania, Austria, Belgium, Bulgaria, Croatia, Cyprus, Czech Republic, Denmark, Estonia, Finland, France, Germany, Greece, Hungary, Iceland, Ireland, Israel, Italy, Latvia, Lithuania, Luxembourg, Netherlands, Norway, Poland, Portugal, Romania, Russian Federation, Slovak Republic, Slovenia, Spain, Sweden, Switzerland, Turkey, Ukraine, United Kingdom 


$$
\begin{aligned}
Y_{i t j}= & \beta_{0}+L M_{i t j} \boldsymbol{\beta}_{1}+L M_{i t j} * \operatorname{Macro}_{t j} \boldsymbol{\beta}_{2}+\text { Macro }_{t j} \boldsymbol{\beta}_{3}+I_{i t j} \boldsymbol{\beta}_{4}+A g e D_{i t j} \boldsymbol{\beta}_{5} \\
& +\operatorname{AgeD}_{i t j} * L M_{i t j} \boldsymbol{\beta}_{6}+\operatorname{AgeD}_{i t j} * L M_{i t j} * \operatorname{Macro}_{t j} \boldsymbol{\beta}_{7}+X_{i t j X}+T_{t T}+u_{t j}+\epsilon_{i j t}
\end{aligned}
$$

In this paper, we build upon the methodology adopted by Nizalova et al. (2021) but we extend it by considering individuals across the life cycle. Namely, Nizalova et al. focus only on young individuals, while we estimate effects across three age groups-young people, middleaged individuals and older people. In this way, we provide a more comprehensive analysis of the role of age in understanding the way in which individual-level unemployment and macroeconomic indicators interact in affecting subjective health and well-being. $Y_{i t j}$ is a vector of dependent variables (i.e., subjective (bad) health, (un)happiness and (dis)satisfaction with life) of person $i$ in year $t$ and country $j$. Regressions for each dependent variable were run separately. $L M_{i t j}$ is a vector of dummy variables indicating types of labour market status, which includes our variable of interest-being unemployed, but also controls for other labour market statuses. Macro $_{t j}$ stands for country level GDP trend and residual term, and country level UR trend and residual term. $A g e D_{i t j}$ is a vector of two dummy variables: young - representing youth aged 15-29, and old-representing someone of pre-retirement age (50-64), with those in the age range of 30-49 being the base category. We use interactions between age dummies and labour market (LM) status, LM status and macro conditions, and the three-way interaction of age dummies, LM status and macro conditions to disentangle multiple aspects of the effect of unemployment on subjective (bad) health and (un)well-being outcomes depending on age and changes in macro conditions in the country. This approach also addresses a potential concern that unemployment effects may be inflated in cross-sectional study designs with endogenous variables, since there is evidence that obtained estimates on the interaction terms are consistent (Nizalova \& Murtazashvili, 2016). $I_{i t j}$ stands for individual level of income. $X_{i t j}$ is a vector of individual level controls, $\mathrm{T}_{\mathrm{t}}$-country-specific year effects, $u_{t j}$ and $\epsilon_{i j t}$ correspond to different levels of error terms.

\subsection{Measures}

\subsubsection{Dependent Variables}

2.2.1.1 Subjective (Bad) Health Participants were asked to rate their general health using a 5 -point scale ranging from $(1)=$ very good to $(5)=$ very bad.

2.2.1.2 (Un)happiness Participants were asked how happy they would say they are, taking all things together on a 10-point scale ranging from $(1)=$ very unhappy to $(11)=$ very happy. Responses were reversed so that high scores indicate low levels of happiness.

2.2.1.3 (Dis)satisfaction with Life Participants were asked how satisfied they were with their life in general on a 10-point scale ranging from $(1)=$ very dissatisfied to $(11)=$ very satisfied. Responses were reversed, with high scores indicating low levels of satisfaction. 


\subsection{Explanatory Variables}

\subsubsection{LM Status}

Individual-level Unemployment-we used a categorical variable distinguishing between the employed (0) and the unemployed (1). Information on employment status was selfreported. Other types of LM statuses were treated as control variables, these include: having an insecure job (permanent vs. temporary contract), being discouraged from work, being in education, being retired, doing housework, or labour market status being identified as 'other', all binary.

\subsubsection{Age Dummies}

Young-an indicator for being of the age between 15 and 29 (1, 0 otherwise); Old-for being between ages of 50 and 64 (1, 0 otherwise).

Country's economic situation was measured by two indicators: the country's Unemployment Rate (UR) ${ }^{2}$ and the level of country's Gross Domestic Product (GDP). ${ }^{3}$ They were expressed as trends and business cycle fluctuations following the methodology adopted by Nizalova et al. (2021). This helps separate the nature of the signal individuals receive from the macroeconomic indicators into anticipated and unanticipated parts. Both macro measures were decomposed using Hodrick-Prescott filtering method, which allows for the smoothed-curve representation of the trend, achieved through modifying parameters adjusting the trend sensitivity to short-term fluctuations (Hodrick \& Prescott, 1997). The measures were demeaned, to allow meaningful interpretations of the main effects in the specifications with interactions (Wooldridge, 2016). We derive the Hodrick-Prescott (HP) trends of UR and GDP growth and their residuals for each country separately using the following equations:

$$
\begin{gathered}
\operatorname{lnGDP_{jt}}=\tau_{G D P j t}+c_{G D P j t} \\
U R_{j t}=\tau_{U R j t}+c_{U R j t}
\end{gathered}
$$

lnGDP is a natural log of a country's GDP per capita level at PPP values; UR - unemployment rate; $\mathrm{j}$ differentiates between countries; $\mathrm{t}$ - time operator for years, $\tau_{G D P}$ and $\tau_{U R t}$ are trend components for the HP filtered GDP and UR, and $c_{G D P}$ and $c_{U R}$ are respective cyclical components. Equations $2 \mathrm{a}$ and $2 \mathrm{~b}$ were estimated for each country separately using macroeconomic data for the years 1996-2014 and Hodrick-Prescott filtering procedure (Baum, 2004). The acquired values were merged with the rest of the ESS data and only 2002-2014 data was used due to ESS availability.

\subsubsection{Control Variables}

In all of the specifications, we controlled for participants' age (in years) and age squared, secondary or tertiary education completion, and indicators for being married/living with

\footnotetext{
2 A share of the unemployed in the total labour force, ILO measure (World Bank, 2016a).

3 Natural log of all final goods and services produced within a country in a given year, measured at purchasing power parity, per capita, in thousands of 2011 international dollars (World Bank, 2016b).
} 
partner or being separated/divorced (all binary variables). Individual income ${ }^{4}$ was included as a control variable to ensure that any potential negative effect observed in well-being outcomes is not driven by the individual income effect. If after controlling for income the effect of unemployment or insecure employment is still observed, it would indicate their impact goes beyond individual financial inconvenience. Furthermore, all specifications account for yearly fixed effects.

\section{Results}

\subsection{Descriptive Statistics}

Descriptive statistics are presented in Table 1. Youth accounts for $22.6 \%$ of the male sample and $21.4 \%$ of female sample. $32.5 \%$ of males and $32.8 \%$ of females are in preretirement age. Average age in the male sample is around 41.5 years and around 41.7 in the female sample. Secondary education was the highest education attainment for $59.4 \%$ of males and $55.4 \%$ of females, while $34.3 \%$ of males and $37.5 \%$ of females completed tertiary education. $59.1 \%$ of male sample and $58.9 \%$ of females identified themselves as married, and $10.1 \%$ of males and $17.1 \%$ of females as divorced. In relation to LM statuses: $5.3 \%$ of males and $4.3 \%$ of females were unemployed, $13.8 \%$ of males and $15.7 \%$ of females were in insecure employment positions, $2 \%$ of males and $1.9 \%$ of females were being discouraged from work, $8.1 \%$ of males and $8 \%$ of females were in education, $7.4 \%$ of males and $7.9 \%$ of females were in retirement, $1.3 \%$ of males and $16.1 \%$ of females doing housework, and $4.1 \%$ of males and $3.8 \%$ of females had a labour status identified as 'other'. These labour market status indications show very little difference between genders apart from housework where results are in line with the gender stereotype for women being more likely to do housework. Income between two genders did not differ much, both means were within the 6th decile, which is the first decile above average income, the only difference was that the mean for women was closer to the average (5th decile) while for men was closer to the upper end of the 6th decile.

Decomposition of LM statuses by age group is presented in Table 2. Out of the three age groups, prime working age category (base) had the highest proportion of employed individuals $(77.5 \%)$, followed by pre-retirement age group $(56.8 \%)$ and youth $(47.5 \%)$. With regard to unemployment, the highest proportion of youth was unemployed $(6.2 \%)$ in comparison to the other two age groups: prime working age (5\%) and pre-retirement $(3.5 \%)$.

\subsection{Main Results}

Results from multi-level regressions are presented in Table 3. Figures 1, 2, 3 and 4 are based on the same results only showing average marginal effects of the three-way interactions between macroeconomic components, individual-level unemployment and age

\footnotetext{
${ }^{4}$ Measured in deciles; due to a change in the survey design from income being expressed as a 12-category variable relevant to each country and its currency (between 2002 and 2006) to it being expressed in deciles in euros (between 2008 and 2014), income deciles for the years 2002-2006 were imputed using uniform random values (L'Ecuyer, 1994).
} 
Table 2 Labour market (LM) status by age group (proportions)

\begin{tabular}{lllll}
\hline LM status & All & Base (30-49) & Young (15-29) & Old (50-64) \\
\hline Employed & 0.641 & 0.775 & 0.475 & 0.568 \\
Unemployed & 0.048 & 0.050 & 0.062 & 0.035 \\
Insecure employment & 0.148 & 0.129 & 0.270 & 0.092 \\
Discouraged from work & 0.019 & 0.017 & 0.022 & 0.022 \\
In education & 0.081 & 0.014 & 0.335 & 0.003 \\
Retired & 0.076 & 0.009 & 0.002 & 0.220 \\
Housework & 0.091 & 0.104 & 0.071 & 0.086 \\
Other LM status & 0.039 & 0.027 & 0.029 & 0.063 \\
No. of obs & 171,172 & 77,687 & 55,899 & 37,586 \\
\hline
\end{tabular}

vector: being young, in pre-retirement age, or in between the two, on health and well-being outcomes in comparison to an employed same age group counterpart respectively (represented by horizontal zero line in Figs. 1, 2, 3 and 4). Graphs were created for men and women separately Table 4.

Regarding Research Question 1, the individual-level unemployment effects on subjective bad health and poor well-being measures across the different age groups, Table 3 shows the effect sizes of individual-level unemployment on all three dependent variables ceteris paribus, i.e. in a country with average GDP and UR growth. Being unemployed was related significantly to an impairment of all three dependent variables for prime employment age, male and female, adults. The increases in (bad) health and (un)well-being measures, however, were smaller for the youth, and only subjective (bad) health of unemployed young males and unhappiness of unemployed young females were not statistically different from middle-aged adults. Coefficients for the differential effects on dependent variables for older adults were mostly insignificant, however, unhappiness of older males and dissatisfaction with life of older females were even higher and significant in comparison to the middle-aged category. In comparison to the employed, individual-level unemployment for men was related to larger increases in (un)well-being measures than it was for women, while the pattern was reversed in the case of subjective (bad) health. Overall, individuallevel unemployment effects were lowest for subjective (bad) health, and highest for life dissatisfaction, suggesting a greater sensitivity of well-being measures than that of health.

In summary, individual-level unemployment was associated with increases in subjective (bad) health and (un)well-being measures for all age groups in countries with average GDP and UR growth. However, where the differential effect on youth was significant, it shows them suffering smaller increases in the dependent variables, and where the differential effect on pre-retirement age adults was significant, it led to larger impairment in the dependent variables. These results indicate a greater vulnerability of older adults.

In regard to Research Question 2, the effects of macroeconomic indicators on the outcomes across the different age groups, Table 3 presents the effects of macroeconomic indicators separately, representing the effects for the employed. These numbers refer to the role of the economic situation in general for the overall population in the absence of significantly different effects for those who are unemployed; they also are a baseline to which other age groups are compared to.

The GDP trend had the most significant and sizeable impact on subjective bad health and un-well-being outcomes in comparison to the other macroeconomic indicators. An 


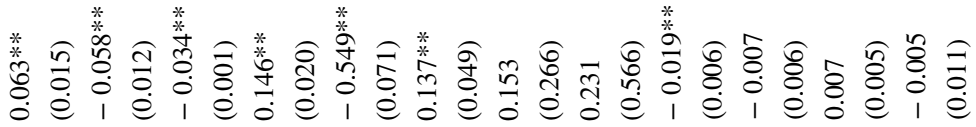

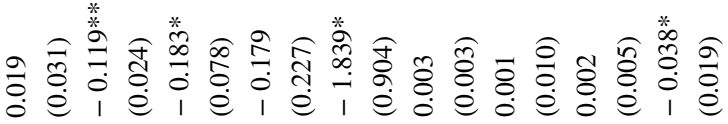

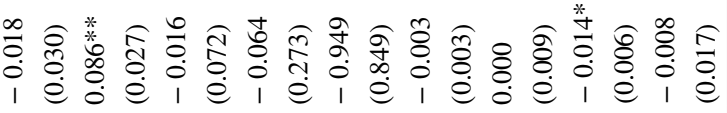

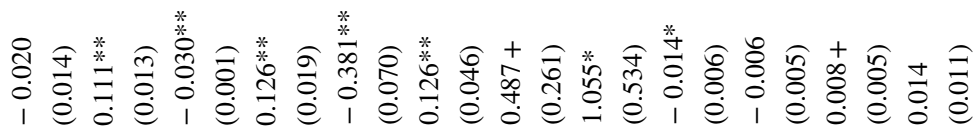
: 


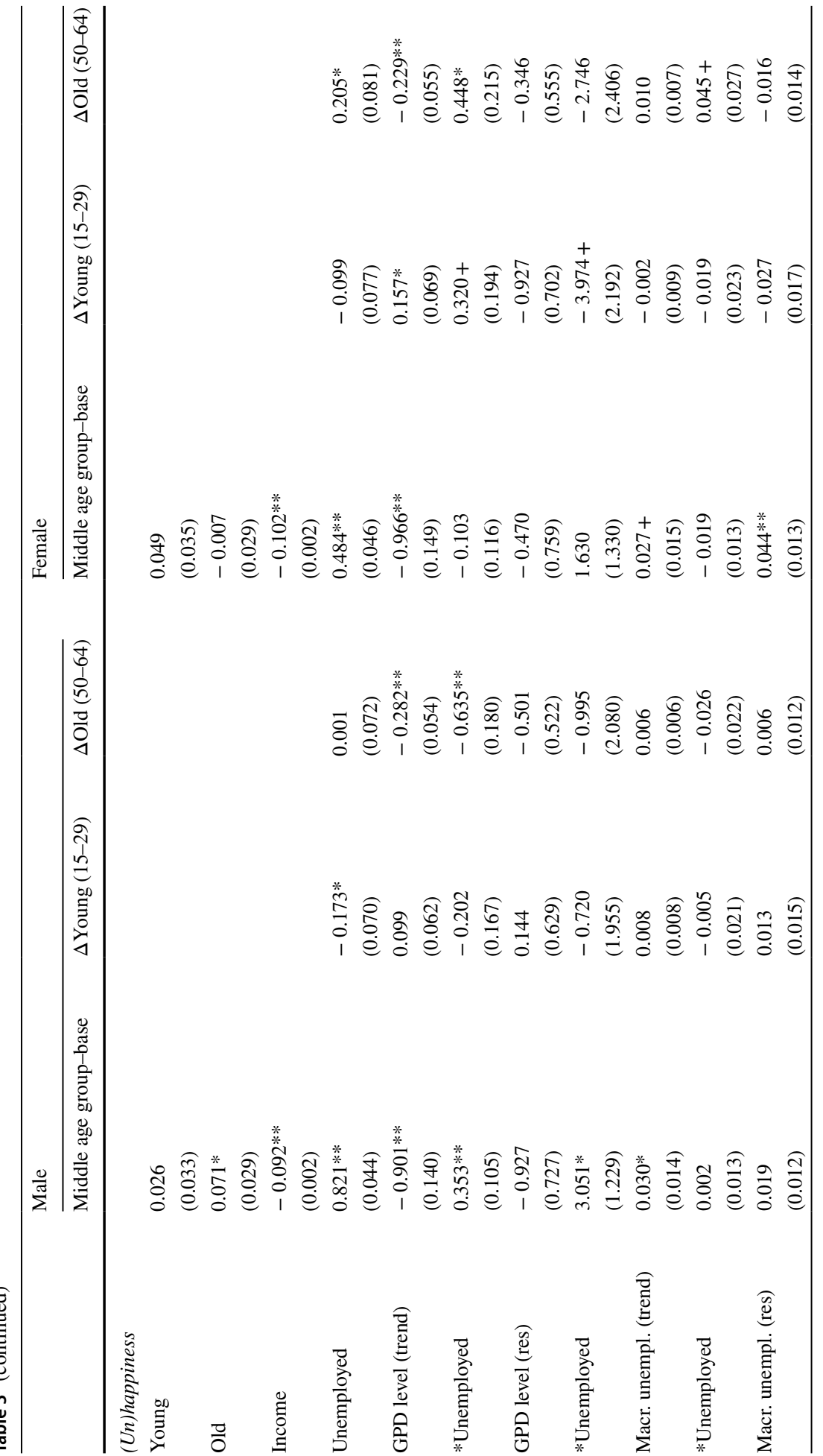




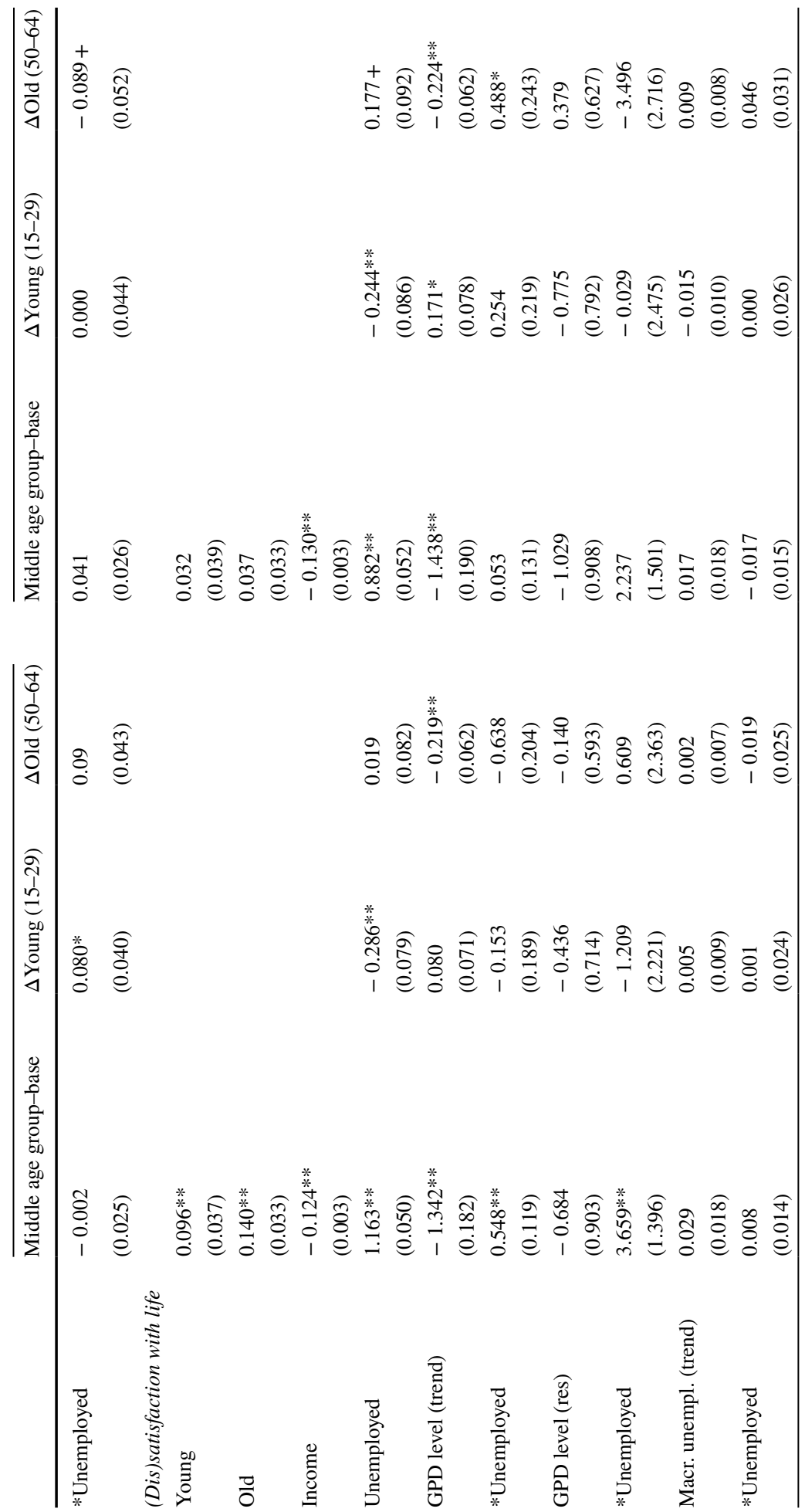




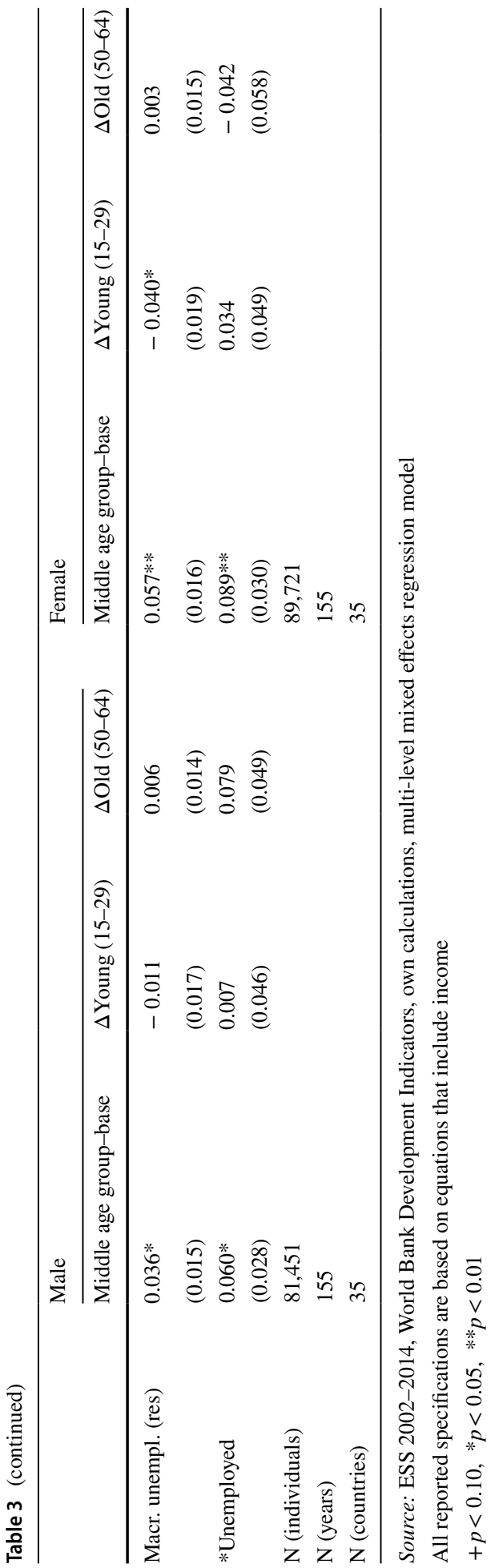

\section{Springer}



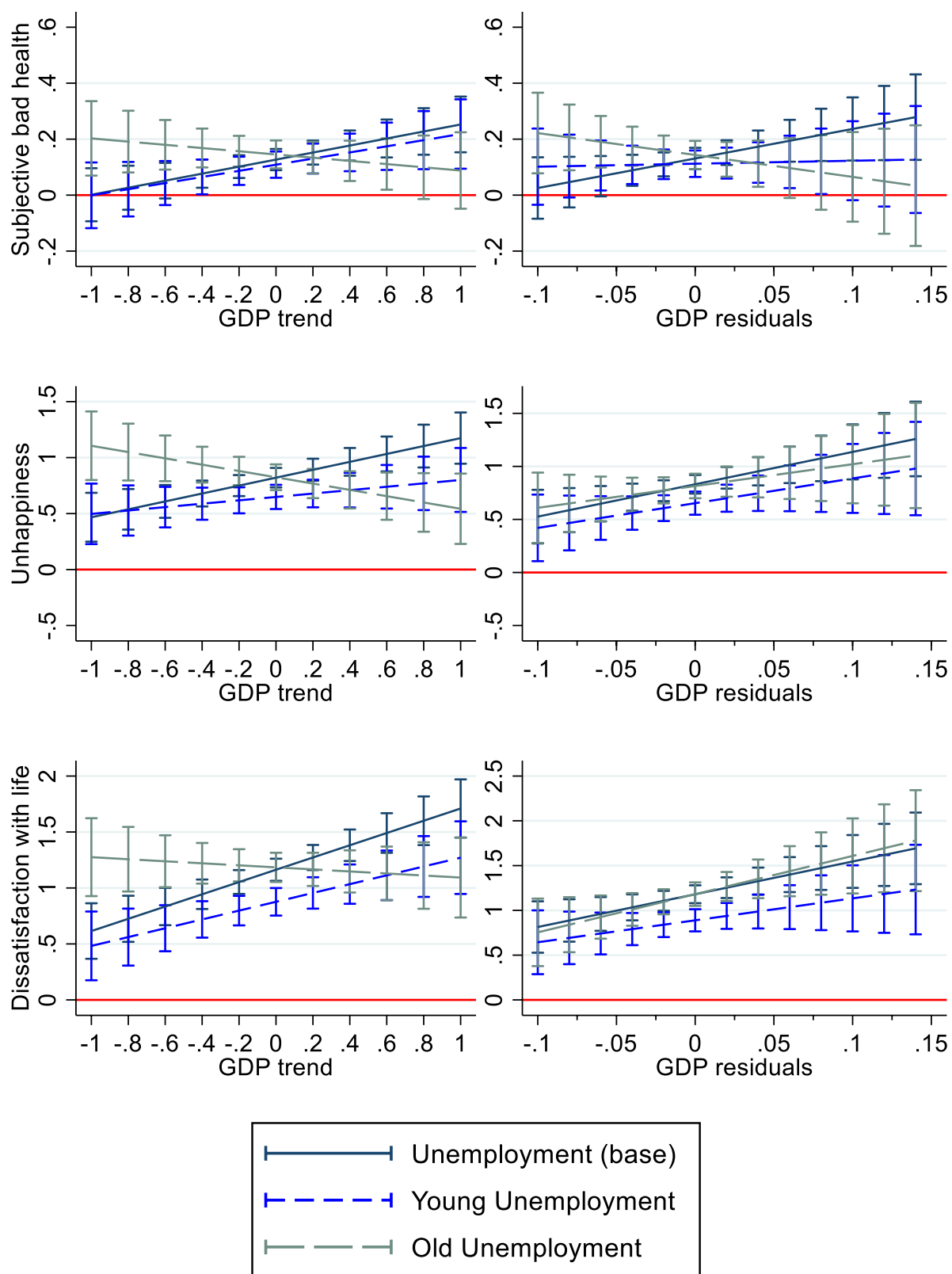

Fig. 1 Male health and well-being responsiveness to changes in GDP-comparison to adult employed-marginal effects (using HP filter)

increase in average GDP trend level reduced all three outcome measures for prime age working adults, with the effects being strongest on dissatisfaction with life and weakest on bad health. Women were found to be more sensitive to GDP trend changes than men in respect to all outcomes, but mostly subjective bad health. There was a further reduction in 

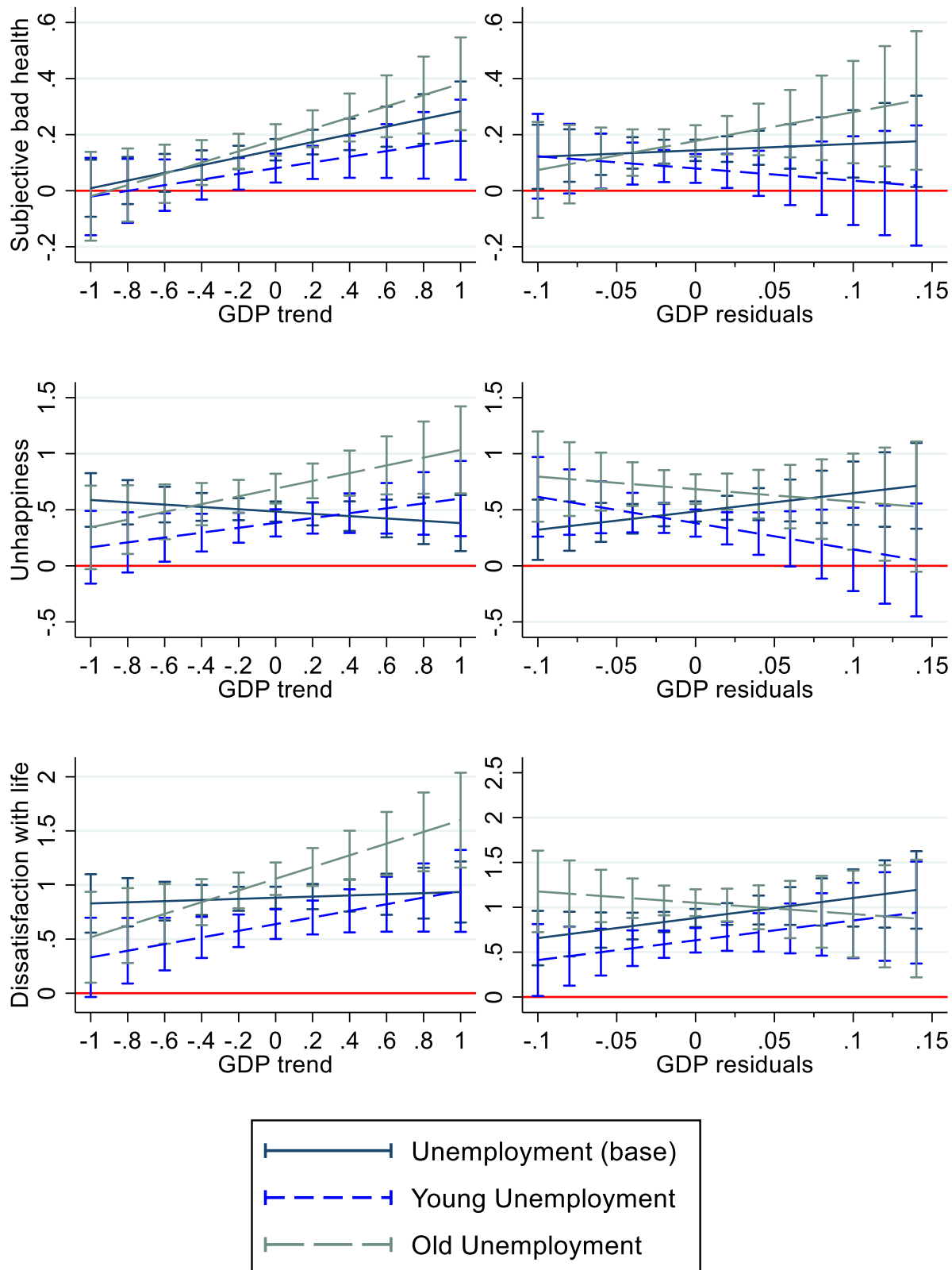

Fig. 2 Female health and well-being responsiveness to changes in GDP-comparison to adult employedmarginal effects (using HP filter)

all outcome variables on pre-retirement age people of both genders, suggesting that growing economy has more of a positive impact on their health and well-being in comparison to middle-aged adults. However, the effects on youth were of the opposite sign. In comparison to prime working age (employed) adults, GDP trend growth reduced bad health 

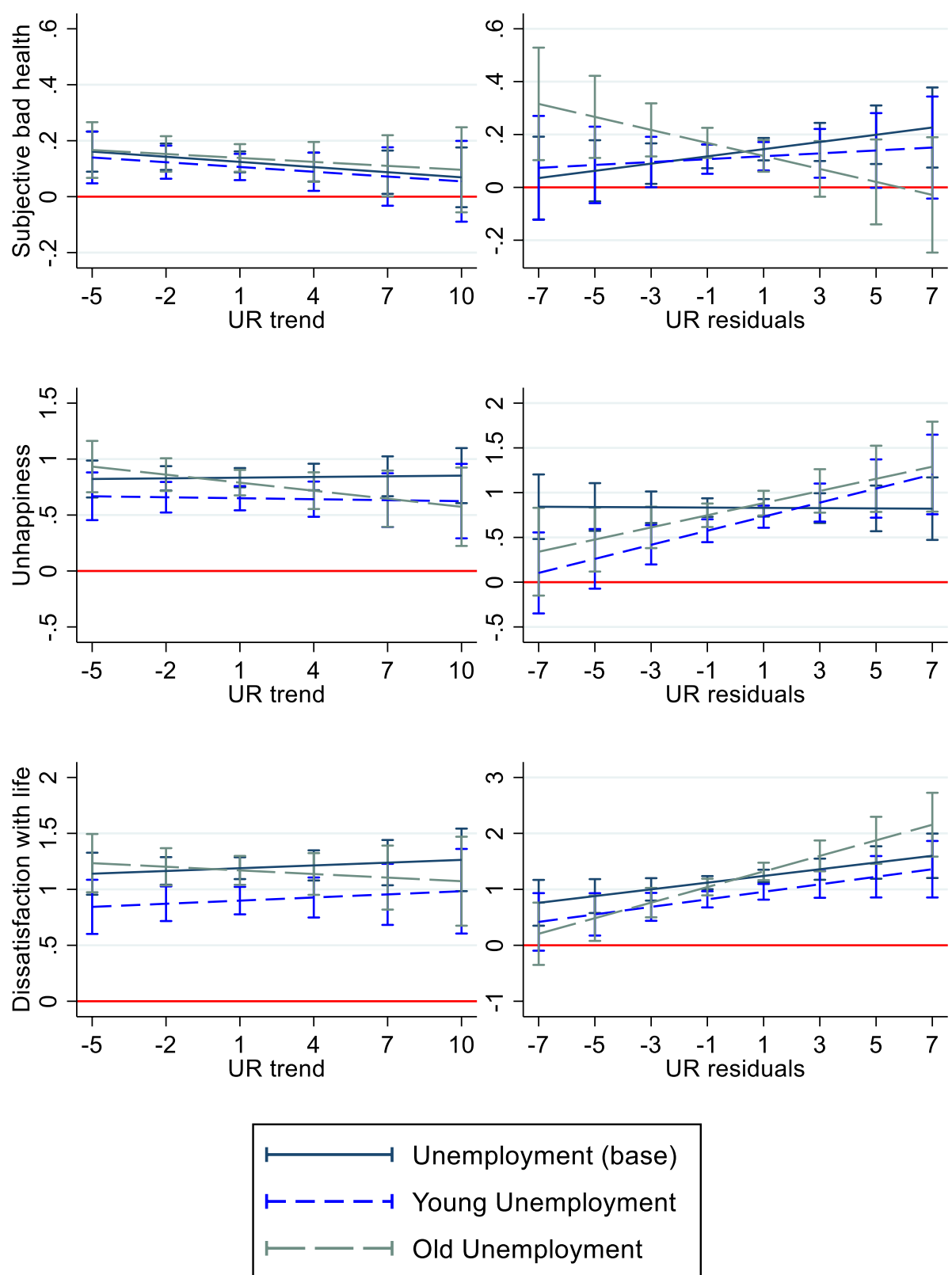

Fig. 3 Male health and well-being responsiveness to changes in UR-comparison to adult employed-marginal effects (using HP filter)

and un-well-being measures less, which was especially true for young (employed) females, but was also observed in subjective bad health of young males. Changes in GDP residuals (shocks) mostly had no significant effects on outcome measures. 

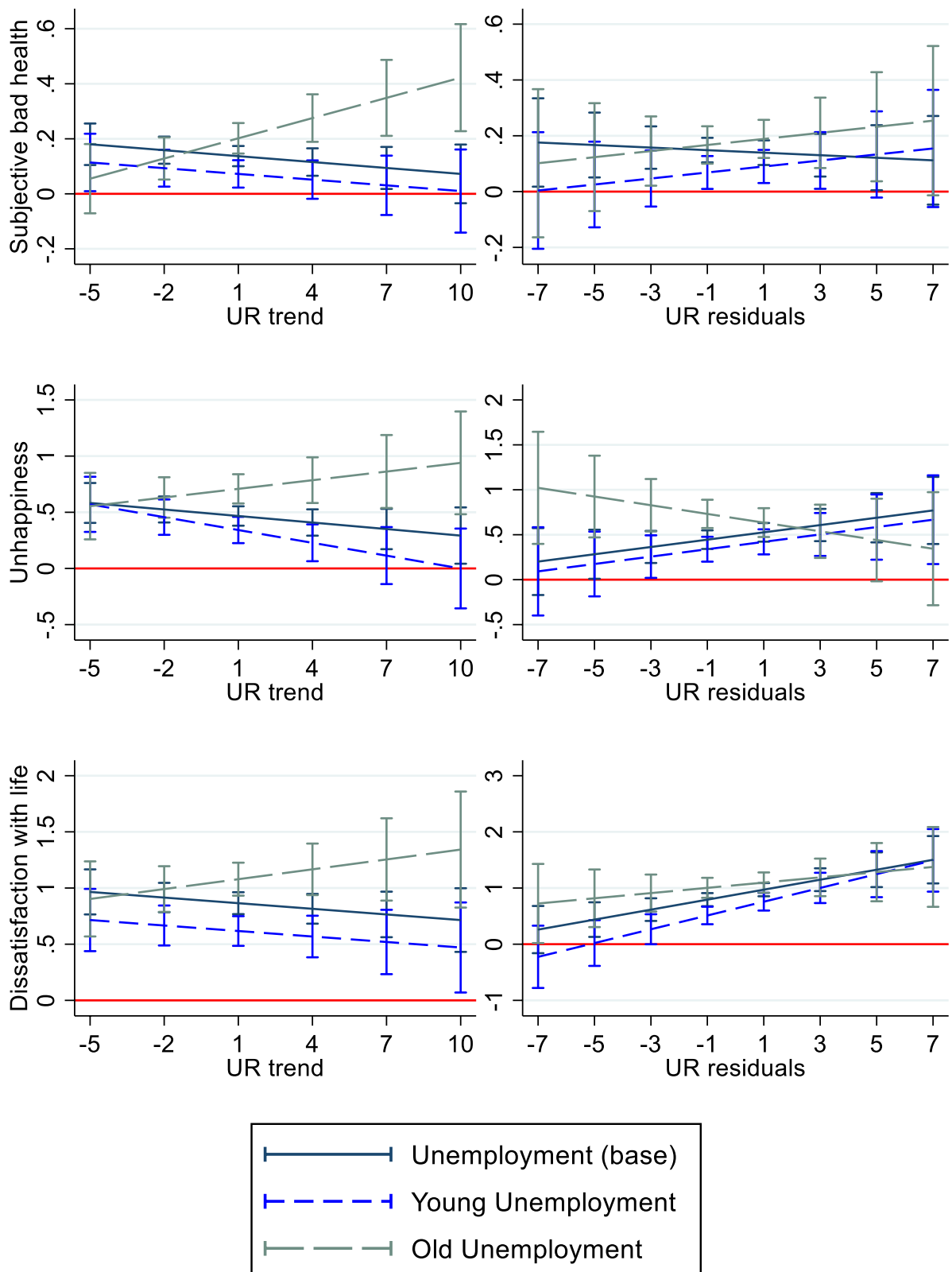

Fig. 4 Female health and well-being responsiveness to changes in UR-comparison to adult employed-marginal effects (using HP filter)

The effects of changes in UR trend were minor and significant only in a few cases. A rise in the unemployment rate above average resulted in a small reduction in impaired health for employed middle-age group adults, both male and female. Coefficients next to other age groups were not significantly different, apart from young females, whose subjective bad 
Table 4 Summary of the moderating effects of macro-indicators on the relationship between individual unemployment and subjective (bad) health and impaired well-being measures, by gender and age group

\begin{tabular}{|c|c|c|c|c|c|}
\hline \multicolumn{3}{|l|}{ Male } & \multicolumn{3}{|c|}{ Female } \\
\hline Base & $\begin{array}{l}\Delta \text { Young } \\
(15-29)\end{array}$ & $\Delta$ Old (50-64) & Base & $\begin{array}{l}\Delta \text { Young } \\
(15-29)\end{array}$ & $\Delta$ Old $(50-64)$ \\
\hline
\end{tabular}

Subjective (bad) health

\begin{tabular}{|c|c|c|c|c|c|c|}
\hline GDP (trend) & $\uparrow$ & - & $\downarrow$ & $\uparrow$ & - & - \\
\hline GDP (res) & $\uparrow$ & - & $\downarrow$ & - & - & - \\
\hline UR (trend) & - & - & - & - & - & $\uparrow$ \\
\hline UR (res) & - & - & $\downarrow$ & - & - & - \\
\hline \multicolumn{7}{|l|}{ (Un)happiness } \\
\hline GDP (trend) & $\uparrow$ & - & $\downarrow$ & - & $\uparrow$ & $\uparrow$ \\
\hline GDP (res) & $\uparrow$ & - & - & - & $\downarrow$ & - \\
\hline UR (trend) & - & - & - & - & - & $\uparrow$ \\
\hline UR (res) & - & $\uparrow$ & - & - & - & $\downarrow$ \\
\hline \multicolumn{7}{|c|}{ (Dis)satisfaction with life } \\
\hline GDP (trend) & $\uparrow$ & - & - & - & - & $\uparrow$ \\
\hline GDP (res) & $\uparrow$ & - & - & - & - & - \\
\hline UR (trend) & - & - & - & - & - & - \\
\hline UR (res) & $\uparrow$ & - & - & $\uparrow$ & - & - \\
\hline
\end{tabular}

Only statistically significant (at 10\% level and below) moderating effects presented;

$\uparrow$ : indicates an increase in outcome measures (i.e. worse subjective health and well-being) with growth of a macroeconomic indicator; $\downarrow$ : indicates a decrease in outcome measures (i.e. better subjective health and well-being) with growth of a macroeconomic indicator;

Results of base category show a relative comparison with employed, results of 'young' and 'old' subgroups present comparisons with the base category. Details of coefficient sizes available in Table 3

health was lowered even further. However, the effect was opposite (i.e., increased) for the unhappiness levels of the prime working age group, with no significant differences with the other age groups. There were no significant effects observed for dissatisfaction with life.

A sudden (unexpected) increase in UR mostly caused small increases in all three outcome variables for employed base age group adults. This includes bad health of males, unhappiness of females and life dissatisfaction for both genders. The effect went the opposite direction for bad health of young employed males, and life dissatisfaction of young employed females. Overall, only changes in GDP trend level were associated with larger significant impact on all dependent variables and all age groups.

To answer Research Question 3, Table 3 presents the moderating effects of individuallevel unemployment and the macroeconomic indicators on outcomes across the different age groups. The moderating effects were expressed as interaction terms between the macroeconomic conditions and individual-level unemployment status. ${ }^{5}$ The results showed that the subjective (bad) health of those who are unemployed changed little with macroeconomic conditions, and mostly was not significantly different from those who are employed.

\footnotetext{
5 Table 3 presents simple summary version of macroeconomic moderating effects on the relationship between individual-level unemployment and subjective (bad) health and impaired well-being.
} 
Being unemployed when GDP level rises above European average was associated with an increase in subjective (bad) health for middle age group (base) males and females in comparison to the employed counterparts. Interaction with GDP residuals (positive shock) increased bad health only for prime working age males, while increases in unemployment rate trend were related to higher bad health for unemployed older females. Reductions in bad health were observed only amongst older males who were unemployed, under all macro conditions' positive changes except for unemployment trend, where the interaction was not significant.

With respect to (un)happiness levels, there was less of an obvious pattern in interaction terms between unemployment and macroeconomic changes. Most interactions with GDP trend were significant: if the GDP trend increased above the European average. Prime working age unemployed males were significantly more unhappy in comparison to employed males of same age, however there was no significant difference between same age employed and unemployed females. However, young and older females had higher unhappiness levels in comparison to same age employed female counterparts. The interaction term for older males was of the opposite sign-they felt substantially less unhappy when unemployed in a growing economy in comparison to older employed males. Only two of unemployment interactions with GDP residuals were significant: prime working age men felt substantially more unhappy if they were unemployed when there was an unexpected rise in GDP, and young unemployed females felt significantly less unhappy in comparison to employed counterparts under the same economic conditions. Increases in country-level unemployment rate significantly affected only older unemployed females who were a little more unhappy. Unemployment shock-term changes significantly affected only young unemployed males, who were somewhat more unhappy than employed young males, and older unemployed females, who were less unhappy.

There were fewer significant moderating effects of macroeconomic indicators for the unemployed regarding dissatisfaction with life. The most sizeable moderating effects were observed for men with GDP level and residual term changes. With positive changes in these macroeconomic indicators, dissatisfaction with life for men increased substantially. This effect was found for men of all age groups and there was no significant difference between them. The effect of GDP trend and residual changes was not the same on women. Only changes in GDP trend level had an impact on dissatisfaction of life, and only for unemployed women in pre-retirement age, who showed higher dissatisfaction levels than employed elderly women. However, no significant difference was observed for the other female age groups and no moderating effects of GDP residual term. There was no evidence of unemployment rate affecting how the unemployed of both genders rated their dissatisfaction with life in comparison to the employed. However, the residual term of the unemployment rate was associated with somewhat increased dissatisfaction of both unemployed men and women in comparison to their employed counterparts, but there was no difference observed between different age groups.

Figures 1, 2, 3 and 4 represent combined effects (i.e., individual-level unemployment and macroeconomic environment by each macroeconomic indicator and gender) to show the full picture of how macroeconomic indicators moderate the effect of unemployment in comparison to the employed, to whom the graphs were normalized to represent the difference (horizontal zero line, represents the employed counterparts). There are a few points worth noting: (a) for all males the difference between employed and unemployed outcomes were largest and most significant for unhappiness and dissatisfaction with life, while subjective bad health differences were smaller and less significant with all macroeconomic indicators; (b) For females the difference between employed and unemployed 
were smaller and less significant for all outcomes in comparison to men, most significant differences were observed in dissatisfaction with life with all macroeconomic indicators; (c) For older men all outcomes decreased with increases in GDP and UR trends and the opposite was true for older women; (d) Patterns of moderating effects for older people were frequently different from the other two age groups and general levels of outcome measures were frequently higher than of other age groups even if the differences between age groups were not always significant; (e) Youth age group's outcomes were mostly below older age groups' for both genders and under all macroeconomic indicator changes; (f) The differences between employed and unemployed of both genders were most significant around average European values ( 0 ) of macroeconomic indicators, this could be due to more countries' macroeconomic indicators being clustered around that mark. This suggests that predictions further away from the macroeconomic averages were less precise; (g) All three outcome measures increased for the unemployed young and prime working age adult men with the GDP trend growth, suggesting they were worse off on all three accounts if country's economy was better off.

In summary, graphs represent differences in unemployment experience in comparison to the employed under different macroeconomic conditions and reveal some perception differences, especially by gender, and show that pre-retirement age people stand out in their outcome measures.

\section{Discussion}

In this paper we aimed to understand how macroeconomic conditions, i.e., trends and shocks of GDP and unemployment rate, influence health and well-being outcomes and moderate the effect of individual-level unemployment on subjective impaired health, unhappiness, and life dissatisfaction of Europeans across three different age groups: youth (15-29), prime working age (30-49) and pre-retirement age (50-64) individuals and gender. Differentiating between GDP and unemployment rate and their trends and shocks helped create specific country profiles and disentangle which macroeconomic influences were most important in determining the outcomes of unemployment on subjective health and well-being. We used the ESS dataset for individual level data and country's unemployment rate and GDP levels were taken from ILO macro estimates from the World Bank database.

In our research we allowed for three types of effects on subjective health and well-being measures: (a) direct effects of individual-level unemployment; (b) direct effects of the macroeconomic environment; (c) and moderating effects of macroeconomic factors on the relationship between individual-level unemployment and outcome measures. In line with previous empirical evidence (Cheng \& Chan 2008; De Witte, 2005; Sverke et al., 2002), individual-level unemployment related to impairments in health, happiness and life satisfaction for both genders, even when controlling for one's individual income. By controlling for individual income, we were able to separate the income effect from the psychological effect of unemployment, which allows for clearer representation of how individual-level unemployment relates to health and well-being over and above the financial inconvenience unemployment may cause. We found that harm caused by individual-level unemployment did not differ much between age groups or the differences were mostly not significant. However, where the differences were significant, health and well-being of youth suffered less and that of people in pre-retirement age more. This could be due to youth frequently 
having more support from other family members (Kilpatrick \& Trew, 1985; McKee-Ryan et al., 2005), while older people are more likely to feel deprived than younger (Stynen et al., 2015).

Regarding the direct effects of macroeconomic indicators, only GDP trend stood out with more consistent, sizeable and significant results. Growth of GDP trend (i.e., a wealthier economic environment) significantly contributed to a reduction in impairment of all three outcome measures. These results can be explained by COR theory (Hobfoll, 1989, 2018) according to which country-level GDP can be viewed as an energy resource at the macro-level of analysis. When this resource is available, health and well-being impairments can be prevented. Interestingly, our results showed that youth tended to benefit from it less and older age group more, in comparison to the prime working age adults. This result is in accordance with previous findings (Broomhall \& Winefield, 1990; Rowley \& Feather, 1987) supporting the beneficial effect stable economy can have on individual health and well-being. Our research findings additionally show this effect to be more beneficial for older vs. younger people. One possible explanation could be associated with growing income inequality, where older households have greater wealth allowing more entrepreneurship opportunities in comparison to younger households (Weller \& Wenger, 2019). However, this difference could be explored in future research for a more definitive explanation.

In relation to the moderating effects of macroeconomic indicators, it was mostly GDP trend changes that made a significant and larger impact on the relationship between individual-level unemployment and health and well-being measures. The existing literature mostly focused on the moderating effects of country-level unemployment, mainly suggesting that the unfavourable impact of individual-level unemployment is weaker in countries where unemployment is more widespread (Clark et al., 2010; Heggeb $\varnothing$ \& Elstad, 2018; Powdthavee, 2007). We extend these findings by showing that when both macroeconomic indicators (GDP and UR) are included, it is the GDP that has a dominant effect. Unemployed men were found to be more responsive to GDP trend changes. Positive changes in GDP trend, indicating growing economy, were found to worsen the relationship between individual-level unemployment and health and well-being particularly for unemployed men. Several theories could offer some explanation to this result. According to relative deprivation theory (Crosby, 1984), when economy is growing men who are unemployed feel more entitled to have a job and if they do not, their health and well-being could decline. Attribution theory (Fiske \& Taylor, 1991) would suggest that under favourable economic circumstances people might attribute their lack of employment to internal reasons, which could result in additional pressure and decreases in well-being. And finally, in line with social identity theory (Tajfel \& Turner, 1986), individual-level unemployment experience could become worse due to the comparison with the growing 'norm' group of employed individuals. Moreover, the differences between employed and unemployed were much more pronounced between men than women, with men suffering more for being unemployed. This points out that the 'breadwinner' role is still seen as relatively important and still mostly attributed to men (Connell, 1991, 1995). Overall, well-being measures appear more sensitive to unemployment experience and macroeconomic changes for both genders in comparison to the subjective health.

After the main unemployment effect was plotted across different macroeconomic conditions, the difference between unemployed youth and prime working age adults was frequently non-significant in outcome measures. In most cases, youth unemployment line was plotted below those of older age groups showing somewhat smaller difference between employment and unemployment experience in comparison to other age groups, suggesting 
youth may suffer less. Attribution theory (Fiske \& Taylor, 1991) offers a possible explanation-being at the stage in life where one is only joining the labour force, there is a lesser expectation to have a job and unemployment could be seen as more natural (i.e., something outside of their control), which could put less pressure on them and as a result on their health and well-being outcomes.

Patterns for older people were found to be different. Older people were frequently the most vulnerable group, i.e. one with highest levels of negative outcome measures. However, there was some variation regarding when their subjective health and well-being would suffer the most: old men were found to suffer more when GDP growth was below average, while old females appeared to suffer more when economic growth was above average or there is high country level unemployment. More targeted research is needed to determine the reasons behind these findings.

\subsection{Practical and Policy Implications}

Our findings show that even though individual-level unemployment has unfavourable effects for individuals' health and well-being, these effects are particularly alarming for people in pre-retirement age (50-65). Unemployed individuals of this age group were also found to often respond the worst to the moderating role of macroeconomic changes. This calls for more support to unemployed individuals in pre-retirement years. At a policy level, this may require further care for pre-retirement age individuals registering for unemployment benefits. This group could also be highlighted as vulnerable in primary care sector requiring occasional psycho-emotional evaluations. At the practical level, some re-employment initiatives have already shown positive results for older unemployed individuals. For example, Aysina et al. (2017) tested the effectiveness of a job interview simulation training (i.e., a computer-based simulator, which allowed unemployed job seekers at the preretirement age to practice interviewing), and found that those participants who followed the training showed decreased heart-rate and increased psychological readiness after the training and in comparison with a control age group. Similarly, Rife and Belcher (1994) showed that participation in Job Club intervention programmes helped pre-retirement age individuals get re-employed.

Our results also revealed that individual health and well-being are more vulnerable to changes by a country's GDP trend rather than a country's unemployment rate. This finding highlights the need to be more sensitive to the needs of working age people when GDP is falling. Active Labour Market Programmes were shown to be particularly effective during financial recession (Card 2018), while creation of networking opportunities for the unemployed helped finding informal contacts for easier re-employment (Bonoli, 2014). However, positive changes in GDP trend (i.e., growing economy) were found to worsen the relationship between individual-level unemployment and health and well-being particularly for unemployed men. This suggests that some programmes should be specifically aimed at supporting psychological and re-employment needs of unemployed men who are significantly less likely to seek psychological help (Spendelow, 2015).

\subsection{Limitations and Overall Conclusion}

This study benefits from a large micro level dataset allowing for a comparison between most European countries and their macroeconomic conditions. However, there are some limitations that should be considered. Data is cross-sectional at the individual level of 
analysis. Being able to follow the same group of individuals across the years would be more informative in terms of individual trajectories. We controlled for a wide range of information that literature suggests could impact subjective health and well-being, but we could not account for family support, and personal savings. Such information could help understand and potentially impact our findings. In an attempt to be more concise and not overly complex when reporting our findings, we focused only on one labour market status-being unemployed. However, as other statuses (e.g., job insecurity) may also have a strong negative impact on health and well-being (Nizalova et al., 2021; Täht et al., 2020), we did control for them in all empirical specifications. Subjective health and well-being measures introduce another limitation-self-reports signal lack of objectivity. However, these measures are widely used in research and, in light of the lack of better alternatives, still produce valuable insights. Finally, our methodology decomposes unemployment and macroeconomic environment effects into many levels, and this also can be considered a limitation due to its complexity and lack of one clear message. However, we felt that offering this detail was beneficial for the research, allowing deeper understanding of how macroeconomic and microeconomic processes interact together in their impact towards health and well-being measures. These limitations could be addressed in future studies with a different focus which could be motivated and partially shaped by the findings of this article.

Acknowledgements The idea for this article emerged during the course of the EXCEPT project (Project's home web address: http://www.except-project.eu/home/), aimed at exploring youth unemployment in Europe. However, this study was outside of the scope and timeline of the project.

Authors' Contributions All authors contributed to the study conception and design. Material preparation, data collection and analysis were performed by Gintare Malisauskaite and Olena Nizalova. The first draft of the manuscript was written by Gintare Malisauskaite and all authors commented on previous versions of the manuscript. All authors read and approved the final manuscript.

Funding The author(s) received no financial support for the research, authorship, and/or publication of this article.

\section{Declarations}

Conflict of interest The author(s) declare that they have no conflict of interest.

Availability of Data and Material This research uses only publically available data.

Code Availability This research employs research specific code for Stata software.

Ethical Approval This research did not involve any human and/or animal participants and did not require ethical approval or informed consent for publication.

Open Access This article is licensed under a Creative Commons Attribution 4.0 International License, which permits use, sharing, adaptation, distribution and reproduction in any medium or format, as long as you give appropriate credit to the original author(s) and the source, provide a link to the Creative Commons licence, and indicate if changes were made. The images or other third party material in this article are included in the article's Creative Commons licence, unless indicated otherwise in a credit line to the material. If material is not included in the article's Creative Commons licence and your intended use is not permitted by statutory regulation or exceeds the permitted use, you will need to obtain permission directly from the copyright holder. To view a copy of this licence, visit http://creativecommons.org/licenses/by/4.0/. 


\section{References}

Artazcoz, L., Benach, J., Borrell, C., \& Cortez, I. (2004). Unemployment and mental health: Understanding the interactions among gender, family roles and social class. American Journal of Public Health, 94(1), 82-88.

Aysina, R. M., Efremova, G. I., Maksimenko, Z. A., \& Nikiforov, M. V. (2017). Using a computer simulation to improve psychological readiness for job interviewing in unemployed individuals of pre-retirement age. Europe's Journal of Psychology, 13(2), 251-268.

Baum, C. F. (2004). HPRESCOTT: Stata module to implement Hodrick-Prescott filter for time series data. Statistical Software Components S447001.

Bonoli, G. (2014). Networking the Unemployed: Can policy interventions facilitate access to employment through informal channels? International Social Security Review, 67(2), 85-106.

Boyczuk, A. M., \& Fletcher, P. C. (2016). The Ebbd and flows: Stresses of sandwich generation caregivers. Journal of Adult Development, 23, 51-61.

Broomhall, H. S., \& Winefield, A. H. (1990). A comparison of the affective well-being of young and middle-aged unemployed men matched for length of unemployment. British Journal of Medical Psychology, 63(1), 43-52.

Card, D., Kluve, J., \& Weber, A. (2018). What works? A meta analysis of recent active labor market program evaluations. Journal of the European Economic Association, 16(3), 894-931.

Cheng, G.H.-L., \& Chan, D.K.-S. (2008). Who suffers more from job insecurity? A meta-analytic review. Applied Psychology, 57(2), 272-303. https://doi.org/10.1111/j.1464-0597.2007.00312.x

Clark, A., Knabe, A., \& Rätzel, S. (2010). Boon or bane? Others' unemployment, well-being and job insecurity. Labour Economics, 17(1), 52-61.

Connell, R. W. (1991). Live fast and die young: The construction of masculinity among young workingclass men on the margin of the labour market. Australia \& New Zealand Journal of Sociology, 27(2), $141-171$.

Connell, R. W. (1995). Masculinities. Polity Press.

Crosby, F. (1984). Relative deprivation in organizational settings. Research in Organizational Behavior, 6 , 51-93.

De Witte, H. (2005). Job insecurity: Review of the international literature on definitions, prevalence, antecedents and consequences. SA Journal of Industrial Psychology, 31, 1-6.

Eichhorn, J. (2013). Unemployment needs context: How societal differences between countries moderate the loss in life satisfaction for the unemployed. Journal of Happiness Studies, 14, 1657-1680.

Fiske, S. T., \& Taylor, S. E. (1991). Social cognition (2nd ed.). McGraw-Hill.

Fryer, D. (1998). Labour market disadvantage, deprivation and mental health. In P.J.D. Drenth, H., Thierry, \& C.J. de Wolff (Eds.), Handbook of work and organizational psychology 2, 215-227. East Sussex, Hove: Psychology Press.

Grosemans, I., Hannes, K., Neyens, J., \& Kyndt, E. (2018). Emerging adults embarking on their careers: Job and identity explorations in the transition to work. Youth \& Society, 52(5), 795-819.

Guardiola, J., \& Guillen-Royo, M. (2015). Income, unemployment, higher education and wellbeing in times of economic crisis: Evidence from Granada (Spain). Social Indicators Research, 120(2), 395-409.

Heggebø, K., \& Elstad, J. I. (2018). Is it easier to be unemployed when the experience is more widely shared? Effects of unemployment on self-rated health in 25 European countries with diverging macroeconomic conditions. European Sociological Review, 34(1), 22-39.

Hobfoll, S. E. (1989). Conservation of resources: A new attempt at conceptualizing stress. American Psychologist, 44, 513-524.

Hobfoll, S. E., Halbesleben, J., Neveu, J. P., \& Westman, M. (2018). Conservation of resources in the organizational context: The reality of resources and their consequences. Annual Review of Organizational Psychology and Organizational Behavior, 5, 103-128.

Hodrick, R., \& Prescott, E. C. (1997). Postwar U.S. business cycles: An empirical investigation. Journal of Money Credit and Banking, 29(1), 1-16.

Jacob, M. (2008). Unemployment benefits and parental resources: What helps the young unemployed with labour market integration? Journal of Youth Studies, 11(2), 147-163.

Kilpatrick, R., \& Trew, K. (1985). Life styles and psychological well-being among unemployed men in Northern Ireland. Journal of Occupational Psychology, 58, 207-216.

L'Ecuyer, P. (1994). Uniform random number generation. Annals of Operations Research, 53, 77-120.

McKee-Ryan, F. M., Song, Z., Wanberg, C. R., \& Kinicki, A. J. (2005). Psychological and physical wellbeing during unemployment: A meta-analytic study. Journal of Applied Psychology, 90, 53-76.

Nizalova, O., Malisauskaite, G., Xanthopoulou, D., Gousia, K., \& Athanasiades, C. (2021). Effects of unemployment and insecure jobs on youth well-being in Europe: Economic development and business cycle 
fluctuations. In M. Unt, M. Gebel, S. Bertolini, V. Deliyanni- Kouimtzis, \& D. Hofäcker (Eds.), Social Exclusion of Youth in Europe (pp. 31-57). Bristol University Press.

Nizalova, O., \& Murtazashvili, I. (2016). Exogenous treatment and endogenous factors: Vanishing of omitted variable bias on the interaction term. Journal of Econometric Methods, 5(1), 71-77.

Oesch, D., \& Lipps, O. (2013). Does unemployment hurt less if there is more of it around? A panel analysis of life satisfaction in Germany and Switzerland. European Sociological Review, 29(5), 955-967.

Paul, K. I., \& Moser, K. (2009). Unemployment impairs mental health: Meta-analyses. Journal of Vocational Behavior, 74, 264-282.

Powdthavee, N. (2007). Are there geographical variations in the psychological cost of unemployment in South Africa? Social Indicators Research, 80(3), 629-652.

Rife, J. C., \& Belcher, J. R. (1994). Assisting unemployed older workers to become reemployed: An experimental evaluation. Research on Social Work Practice, 4(1), 3-13.

Rowley, K. M., \& Feather, N. T. (1987). The impact of unemployment in relation to age and length of unemployment. Journal of Occupational Psychology, 60, 54-98.

Spendelow, J. S. (2015). Cognitive-behavioral treatment of depression in men: Tailoring treatment and directions for future research. American Journal of Men's Health, 9(2), 94-102.

Stynen, D., Forrier, A., Sels, L., \& De Witte, H. (2015). The relationship between qualitative job insecurity and OCB: Differences across age groups. Economic and Industrial Democracy, 36, 383-405.

Sverke, M., Hellgren, J., \& Naswall, K. (2002). No security: A meta-analysis and review of job insecurity and its consequences. Journal of Occupational Health Psychology, 7, 242-264.

Täht, K., Xanthopoulou, D., Figgou, L., Kostouli, M., \& Unt, M. (2020). The role of unemployment and job insecurity for the well-being of young Europeans: Social inequality as a macro-level moderator. Journal of Happiness Studies, 21(7), 2355-2375.

Tajfel, H., \& Turner, J. C. (1986). The social identity theory of inter-group behavior. In S. Worchel \& L. W. Austin (Eds.), Psychology of intergroup relations (pp. 33-48). Nelson-Hall.

Tesser, A., Millar, M., \& Moore, J. (1988). Some affective consequences of social comparison and reflection processes: The pain and pleasure of being close. Journal of Personality and Social Psychology, 54, 49-61.

Voßemer, J., \& Eunicke, N. (2015). The impact of labor market exclusion and job insecurity on health and well-being among youth-A literature review. EXCEPT Working Papers, WP No 2. Tallinn University, Tallinn. Retrieved Oct 11, 2018 from https://www.except-project.eu/files/filemanager/files/WP2_The_ impact_of_labor_market_exclusion_and_job_insecurity_on_health_and_well-being_among_youth_ literature_review.pdf.

Weller, C. E., \& Wenger, J. B. (2019). Divergent fortunes: Growing wealth inequality and widening entrepreneurship by age. Review of Social Economy, 77(3), 326-360.

Wooldridge, J. M. (2016). Introductory econometrics: A modern approach (6th ed.). Cengage Learning.

World Bank (2016a). Unemployment. Retrieved Aug 20, 2016, from: http://data.worldbank.org/indicator/ SL.UEM.TOTL.ZS

World Bank (2016b). GDP, PPP. Retrieved Aug 20, 2016, from: http://data.worldbank.org/indicator/NY. GDP.MKTP.PP.CD

Wulfgramm, M. (2014). Life satisfaction effects of unemployment in Europe. The moderating influence of labour market policy. Journal of European Social Policy, 24, 258-272.

Publisher's Note Springer Nature remains neutral with regard to jurisdictional claims in published maps and institutional affiliations. 